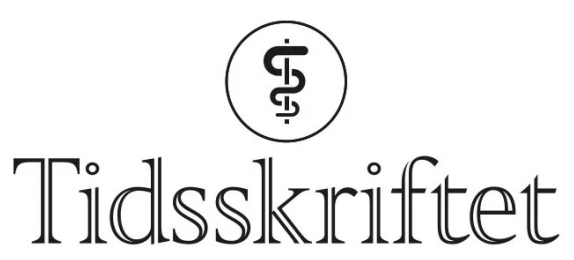

DEN NORSKE LEGEFORENING

\title{
Er EEG en nyttig undersøkelse i voksenpsykiatrien?
}

\author{
OVERSIKTSARTIKKEL
}

\section{TROND SAND}

Trond Sand (f. 1952) er spesialist i klinisk nevrofysiologi og nevrologi. Han er seksjonsoverlege ved Seksjon for nevrofysiologi og professor i klinisk nevrofysiologi.

Forfatter har fylt ut ICMJE-skjemaet og oppgir ingen interessekonflikter.

Email: trond.sand@ntnu.no

St. Olavs hospital

og

Institutt for nevromedisin

Norges teknisk-naturvitenskapelige universitet

\section{MARTE HELENE BJØRK}

Marte Bjørk (f. 1980) er ph.d. i nevrovitenskap og har forskningserfaring med EEG. Hun er lege i spesialisering i nevrologi og postdoktor innenfor epilepsi.

Forfatter har fylt ut ICMJE-skjemaet og oppgir følgende interessekonflikter: Hun mottok Pfizer-prisen i 2010 og har mottatt reisestøtte fra GlaxoSmithKline.

Haukeland universitetssykehus

og

Institutt for klinisk medisin

Universitetet i Bergen

\section{ARNE EINAR VAALER}

Arne E. Vaaler (f. 1954) er spesialist i psykiatri. Han er overlege og førsteamanuensis.

Forfatter har fylt ut ICMJE-skjemaet og oppgir ingen interessekonflikter.

St. Olavs hospital

og

Institutt for nevromedisin

Norges teknisk-naturvitenskapelige universitet

\section{BAKGRUNN}

Vi presenterer en kortfattet oversikt over bruk av EEG i psykiatrien, spesielt med vekt på differensialdiagnostisk utredning ved akutte psykiatriske tilstander.

\section{KUNNSKAPSGRUNNLAG}

Artikkelen er basert på litteratursøk i PubMed og forfatternes egne artikkelsamlinger og erfaringer.

\section{RESULTATER}


Epilepsi, encefalitt eller annen hjernesykdom kan debutere med psykiatriske og kognitive symptomer. Langsom EEG-aktivitet kan være et uspesifikt tegn på hjernesykdom.

Psykiatriske pasienter har også $ø$ kt risiko for å få epilepsi. Ved anfallssymptomer som kramper eller tilstander med hurtige endringer i affekt, er epileptiform aktivitet på EEG et spesifikt tegn på epileptisk etiologi eller komorbidetet. Kvantitativ frekvensanalyse (QEEG) er nyttig i forskning og unntaksvis som et supplement i klinisk virksomhet. Ingen QEEGmetoder er så langt blitt akseptert som pålitelig selvstendige markører for psykiatrisk sykdom eller behandlingsrespons.

\section{FORTOLKNING}

EEG bør tas ved nyoppståtte psykoser og ved tilstander med fluktuerende eller progredierende tap av kognitiv funksjon. Voksenpsykiatriske pasienter med anfallssymptomer og tilstander med hurtige endringer i affekt bør også henvises til EEG.

Elektroencefalografi (EEG) er først og fremst nyttig i diagnostikken av epilepsi og andre hjernesykdommer (1), men det er flere grunner til at EEG også er en viktig undersøkelse i psykiatrisk praksis. For det første er det komorbiditet mellom alvorlig psykiatrisk sykdom og epilepsi. Depresjon rammer mange pasienter med epilepsi $(\underline{2}, 3)$. Samtidig har pasienter med depresjon tre til sju ganger økt risiko for å utvikle epilepsi (4). Det er også påvist en tilsvarende relasjon mellom schizofreni og epilepsi (5). Epileptiske anfall kan også imitere psykiatrisk sykdom eller utløse episoder med psykiatriske symptomer.

For det andre vil en rekke akutte og subakutte hjernesykdommer kunne gi emosjonelle eller kognitive hovedsymptomer. Eksempelvis kan frontale hjernesvulster, autoimmune encefalitter eller lewylegemedemens ved Parkinsons sykdom debutere med psykiatriske symptomer og pasienten således først bli henvist til psykiatrisk vurdering.

En siste problemstilling er knyttet til klassifisering av psykiatriske lidelser. Kan en kvantitativ analyse av EEG-bølgenes frekvensinnhold (QEEG) bidra ved psykiatrisk diagnostikk og behandling? Dette spørsmålet har opptatt forskere og klinikere i en årrekke $(\underline{6}, 7$.$) .$

Hensikten med denne artikkelen er å gi en kortfattet oversikt over forskning og praktisk klinisk bruk av EEG i voksenpsykiatrien

\section{Kunnskapsgrunnlag}

Artikkelen bygger på et litteratursøk i PubMed med søkeordet «EEG» kombinert med henholdsvis «depression», «bipolar disorder» og «schizophrenia». I tillegg er artikkelen basert på forfatternes egne artikkelsamlinger og erfaring med EEG i klinisk nevrofysiologi, nevrologi og psykiatri. Vi har lagt vekt på en gjennomgang av kontrollerte originalarbeider fra de siste 25 år, samt oversiktsartikler fra de mest toneangivende forskningsmiljøene.

\section{EEG og kvantitativt EEG (QEEG)}

EEG-signalet lages av synkroniserte synapsepotensialer i hjernebarken og fremstår som bølgeformer som er sammensatt av ulike frekvenser og rytmer. Hos friske og våkne voksne består EEG i hovedsak av 8-13 Hz alfabølger og noe 14-30 Hz betabølger, mens det er lite 4-7 $\mathrm{Hz}$ thetabølger og nærmest ingen synlige 0,5-3 Hz deltabølger. Tabell 1 fremstiller i hvilke nevrale nettverk de ulike frekvensene kan gjenfinnes $(\underline{8})$. Ved døs og søvn blir det mer langsomme bølger i EEG. Medikamenter som virker på hjernen kan også endre hastigheten av EEG-rytmene.

\section{Tabell 1}


EEG-bølgefrekvenser som gjenfinnes i nevrale nettverk. Delvis forenklet etter tabell $1 \mathrm{i}$ Uhlhaas \& Singer (8). Gjengitt med tillatelse fra Macmillan Publishers Ltd: Nature Reviews Neuroscience $(\subset) 2010$

\begin{tabular}{|c|c|c|}
\hline EEG-rytme & Anatomi & Funksjon \\
\hline $\begin{array}{l}\text { Delta }(0,5-3 \\
\mathrm{Hz})\end{array}$ & Thalamus, cortex & $\begin{array}{l}\text { Sensorisk "gating". Dyp ikke-REM- } \\
\text { søvn. Hukommelse. }\end{array}$ \\
\hline $\begin{array}{l}\text { Theta }(4-7 \\
\mathrm{Hz})^{1}\end{array}$ & $\begin{array}{l}\text { Hippocampus, sensorisk cortex, } \\
\text { prefrontal cortex }\end{array}$ & Hukommelse, synaptisk plastisitet \\
\hline $\begin{array}{l}\text { Alfa }(8-13 \\
\mathrm{Hz})^{1}\end{array}$ & $\begin{array}{l}\text { Thalamus, hippocampus, sensorisk } \\
\text { og motorisk cortex }\end{array}$ & Oppmerksomhet, bevissthet \\
\hline $\begin{array}{l}\text { Beta }(14-30 \\
\mathrm{Hz})^{1}\end{array}$ & Hele cortex, basalgangliene & $\begin{array}{l}\text { Sensorisk "gating", oppmerksomhet, } \\
\text { motorisk kontroll }\end{array}$ \\
\hline $\begin{array}{l}\text { Gamma (31- } \\
100 \mathrm{~Hz})\end{array}$ & Alle hjernestrukturer & $\begin{array}{l}\text { Sansing, oppmerksomhet, } \\
\text { hukommelse, bevissthet, synaptisk } \\
\text { plastisitet }\end{array}$ \\
\hline [i] & & \\
\hline
\end{tabular}

$[\mathrm{i}]^{1}$ Medvirker også til synkronisering mellom hjerneregioner

Epileptiform aktivitet består av skarpe bølger eller «spike-wave»-mønster. Dette er et svært sikkert tegn på epilepsi dersom pasienten også har anfallssymptomer som kan passe med diagnosen. Sannsynligheten for å finne epileptiform aktivitet hos en pasient med epilepsi $\emptyset$ ker dersom EEG tas under søvn (9.).

Med fremveksten av moderne datamaskiner ble frekvensanalyse basert på FFT (fast fourier transformation) utforsket i psykiatri og nevrologi $(9, \underline{10})$. Frekvensanalysen gir oss tallverdier for mengden delta-, theta-, alfa- og betaaktivitet og fordelingen kan fremstilles i et xy(frekvens/mengde)-diagram (fig 1). Frekvensanalyse (QEEG) er innebygd i mange av de kommersielle EEG-systemene som er i bruk i Norge i dag. Ukvalifisert overforbruk av QEEG i klinisk virksomhet på 199o-tallet ble kritisert av den amerikanske nevrologiforeningen som fastslo at QEEG alltid måtte benyttes sammen med vanlig EEG tolket av nevrofysiolog (ㅁ). Bakgrunnen for dette er at det finnes mange feilkilder som må elimineres før man kan stole på at QEEG-analysen gir riktig resultat. QEEG er imidlertid et nyttig forskningsverktøy. Med utviklingen av analyseprogrammer med brukervennlig grensesnitt og større dataprosessorer er nå forskning på QEEG ved psykiatriske tilstander i rask fremvekst (7.). 


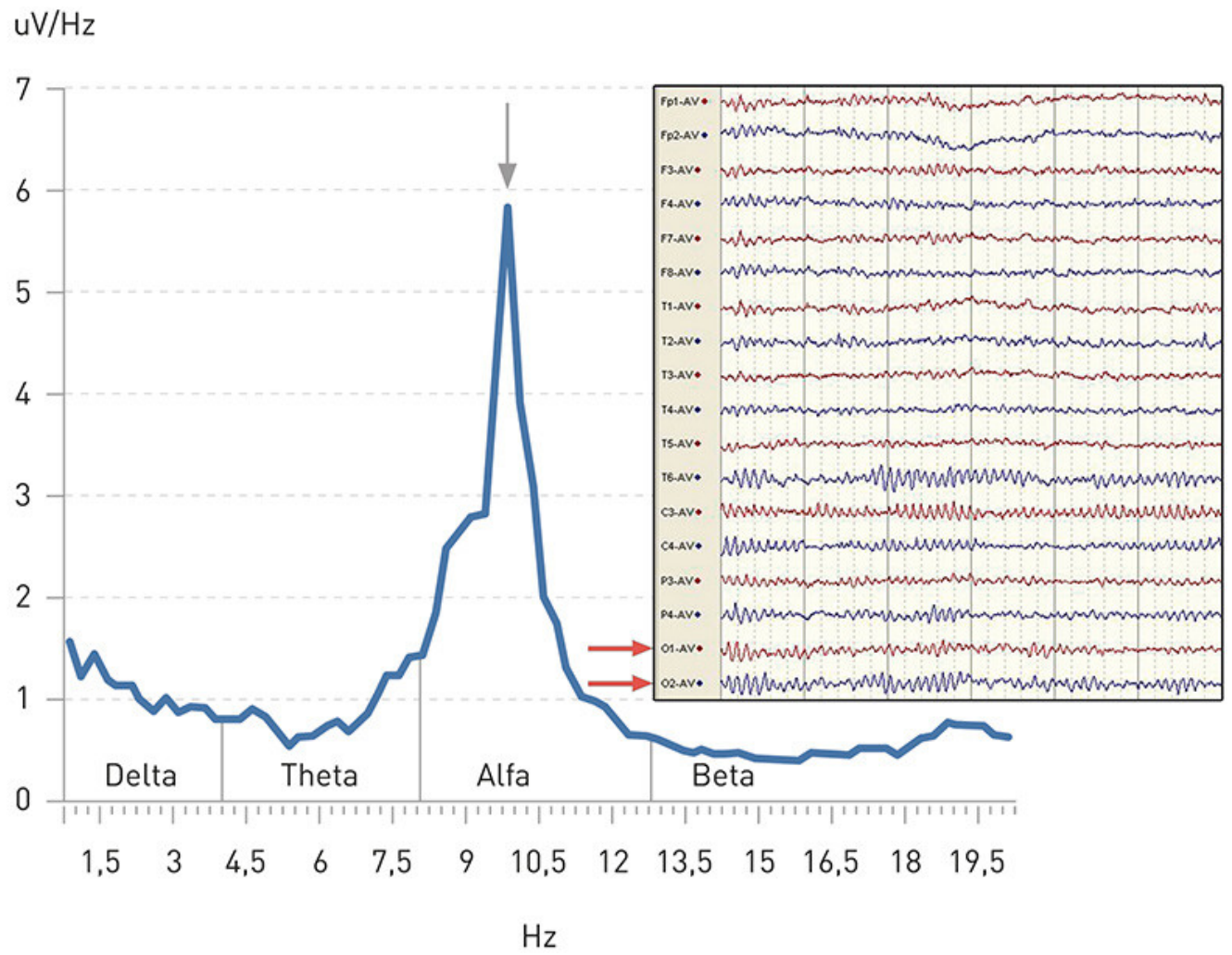

Figur 1 Normalt voksen-EEG i våkenhet med lukkede øyne er vist sammen med en tilhørende frekvenskurve. Den blå kurven er resultatet av en QEEG-analyse fra synscortex basert på 103 sekunder artefaktfritt EEG og viser gjennomsnittskurven fra elektrode O1 og $\mathrm{O} 2$ (røde horisontale piler). Kurven viser amplitude per $\mathrm{Hz}$ (y-akse) som en funksjon av EEG-frekvens (x-akse). Amplituden per Hz er et mål på hvor hyppig og energirik EEGaktiviteten er som funksjon av frekvensinnholdet. Deltaaktivitet, thetaaktivitet, alfaaktivitet og betaaktivitet kan også beregnes som arealet under kurven (i $\mu \mathrm{V})$ mellom de vertikale linjene som markerer grensen mellom frekvensområdene. Alfarytmefrekvensen (svart pil - toppunktet på kurven) er normal =9,75 Hz. Bemerk at det er relativt lav thetaamplitude (mellom 4 og 7,75 Hz) og deltaamplitude (mellom o,75 og 3,75 Hz) i et normalt EEG.

\section{EEG og kognitive prosesser - biologisk bakgrunn}

Kan EEG-rytmene fortelle noe om våre kognitive evner eller emosjonelle stabilitet? Ny forskning viser at rytmisk aktivering av nevrale nettverk, spesielt innen thetaområdet, har stor betydning for hukommelse og andre basale hjernefunksjoner (1ㅡ) (tab 1). Spesielt raske 31-100 Hz gammabølger (프), i samspill med thetarytmer, antas å reflektere de grunnleggende nevrobiologiske mekanismene som sørger for å knytte nye erfaringer til gamle minner (assosiasjon) og overføre relevant ny erfaring til langtidshukommelsen (13). På den annen side er det ingen sikker sammenheng mellom alfarytmens frekvens og intelligens så lenge alfarytmen holder seg innen normalområdet 9-13 Hz (14).).

Andre nye QEEG-metoder som lavoppløst elektromagnetisk tomografi (LORETA) (15) gir informasjon om kilder til EEG-rytmer i dypere deler av hjernen. Samvariasjonsanalyse (koherens- eller konkordansanalyse) (트) viser hvilke deler av hjernen som samarbeider under utførelse av forskjellige oppgaver. Slik kan QEEG supplere funksjonell MR og benyttes for å kartlegge hjernens «funksjonelle nettverk» hos friske og syke.

\section{Akutte psykiatriske symptomer}


Nevrologiske hjernesykdommer kan debutere med psykiatriske symptomer, f.eks. i form av nyoppstått psykose eller fluktuerende eller progredierende tap av kognitiv funksjon (1․,18). EEG er derfor nyttig i utredningen og kan for eksempel bidra til å skille mellom «bipolar lidelse» og «organisk tilstand med bipolare symptomer» (19).

Noen ganger kan vi finne en klar økning av langsomme theta- og deltabølger. Den kliniske nevrofysiologen som tolker EEG, vil først vurdere om en økning i langsom thetaaktivitet

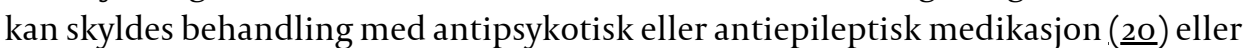
døsighet. Langsomme deltabølger er som regel et uspesifikt tegn på hjernesykdom som for eksempel hjernetumor, infeksjon/abscess, limbisk encefalitt, cerebrovaskulær sykdom, degenerativ, inflammatorisk eller demyeliniserende hjernesykdom eller en toksisk/metabolsk encefalopati. Hos pasienter med akutte psykiatriske symptomer uten kjente underliggende cerebrale patologiske forandringer som får påvist langsom EEG-

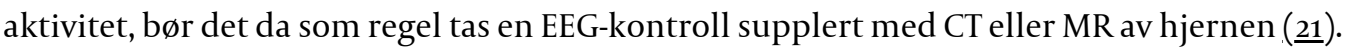

\section{Psykiatriske tilstander øker risikoen for epilepsi}

Pasienter med psykotiske og affektive tilstander vil ha en økt risiko for å utvikle epilepsi (5, 6). Årsakssammenhengen er kompleks og inkluderer antakelig nevrobiologiske, psykososiale og/eller iatrogene mekanismer (므). En undergruppe med tilbakevendende, kortvarige ustabile depresjoner har ofte et unormalt EEG (fig 2), og har hyppigere

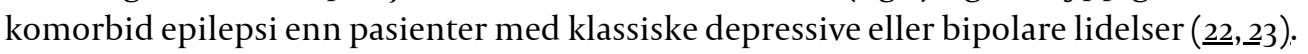

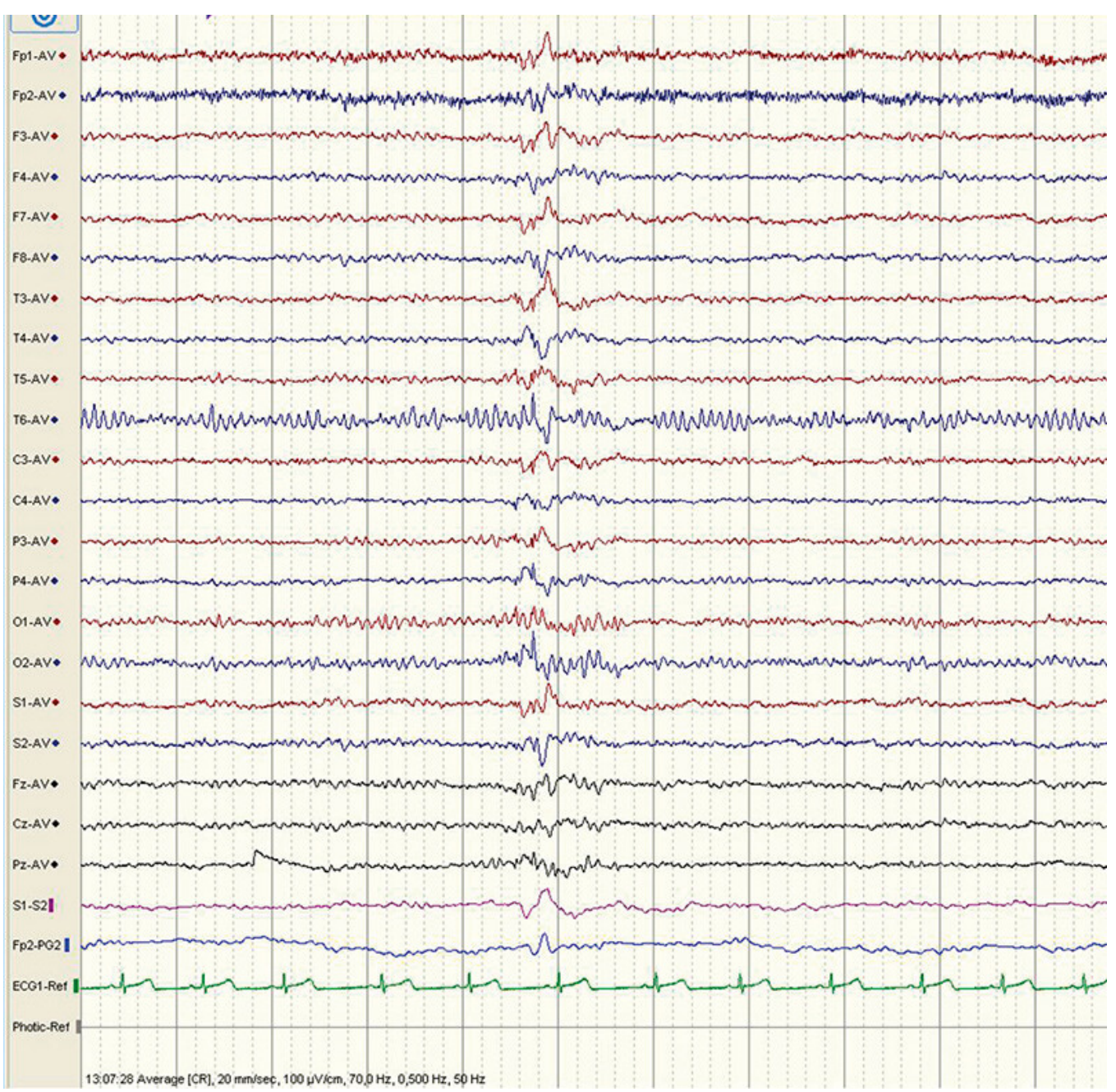

Figur 2 EEG fra forsøksperson med akutte depressive perioder. Normal bakgrunnsaktivitet. Ett enkelt kort, generalisert asymmetrisk utbrudd med atypiske spikes kan ses 
I en retrospektiv observasjonsstudie av klinisk EEG i akutt psykiatri fra 2006 ble unormalt EEG påvist hos $17 \%$ (24). . Litt under halvparten hadde kjent epilepsi, men EEG-resultatet endret behandlingen kun hos 1-2 \% (224). Denne studien var retrospektiv og omfattet få EEGer. Den reelle betydningen av EEG kan etter vår erfaring være høyere, også fordi vi i dag har bedre tilgang til MR-undersøkelser og bruker mer antiepileptika i psykiatrien. Selv om de fleste EEG-er er normale, kan resultatet være svært viktig for de pasientene som har funn på undersøkelsen. EEG bør derfor utføres ved tilstander med hurtige endringer i affekt, ved kramper og ved andre kortvarige, stereotype anfallspregede symptomer.

\section{Psykiatriske symptomer kan forårsakes av epilepsi}

Epileptiske anfall kan likne psykiatrisk sykdom. Vedvarende epileptiske anfall slik som kompleks partiell status epilepticus (KPA-status, ikke-konvulsiv status) kan gi langvarig bevissthetsnedsettelse, automatismer, affektive endringer, forvirring, amnesi, frykt eller schizofreniforme symptomer (25). Temporallappsepilepsi kan medføre plutselig, forbigående angst eller dyp fortvilelse (3,25). Frontallappsepilepsi kan gi anfall med bisarr oppførsel. Viktige differensialdiagnoser er blant annet panikkangst, parasomni og psykogene anfall.

Depressive eller psykotiske episoder kan også komme i tidsmessig relasjon til et epilepsianfall. Mange pasienter med epilepsi rapporterer prodromale endringer i humør 13 døgn før anfall. Epileptiske anfall kan også etterfølges av forbigående psykiatriske symptomer, slik som postiktal psykose og postiktal depresjon. Typisk er et symptomfritt intervall på opptil en uke $(3,25)$.

Ettersom epilepsi og psykiatriske sykdommer altså kan være vanskelige å skille, bør pasienter med akutte psykiatriske symptomer ofte undersøkes både av psykiater og nevrolog, inkludert EEG, enten de har kjent epilepsi eller ikke.

\section{Behandlingsmessige konsekvenser av epileptiform EEG- aktivitet}

Finner vi epileptiform aktivitet i EEG, skal en nevrolog vurdere om det foreligger en klinisk epilepsi eller ikke. Psykiatriske lidelser og symptomer som skyldes pågående epileptisk aktivitet, skal behandles med antiepileptika. Behandling med slike midler kan unntaksvis være nødvendig selv om EEG ikke viser epileptiform aktivitet fordi iktale og postiktale

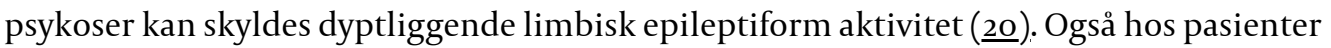
uten epilepsi kan behandling med antiepileptika være indisert hos noen pasienter, selv om en Cochrane-gjennomgang anbefalte at karbamazepin ikke skulle brukes rutinemessig $\mathrm{i}$ schizofrenibehandlingen (므). Patologiske funn på EEG vil øke indikasjon for bruk av antiepileptika sammenliknet med andre psykotrope medikamenter uansett psykiatrisk hovedsymptom $(\underline{27}, \underline{28})$.

\section{Er QEEG nyttig i praktisk nevropsykiatrisk diagnostikk?}

\section{ALVORLIG DEPRESJON OG BIPOLAR LIDELSE}

En kjent forskningsgruppe har benyttet QEEG til å identifisere unipolar og bipolar depresjon med sensitivitet og spesifisitet over $83 \%$ (므). Den anvendte QEEG-metoden er imidlertid ikke allment akseptert som klinisk nyttig. Det er spesielt sparsomme funn i litteraturen om bipolar lidelse, og man har i eldre studier ofte slått sammen bipolar lidelse og alvorlig depresjon i analysene (29). De fleste med akutt mani har normalt EEG (30). Hos pasienter med alvorlig depresjon er det også rapport varierende funn, bl.a. økt mengde høyresidig deltaaktivitet (31). Mani-liknende episoder hos pasienter med epilepsi er også 
assosiert med høyresidig hjernedysfunksjon (205). På den annen side ble det i en blindet studie verken observert $\emptyset \mathrm{kt}$ deltaaktivitet eller asymmetri (32). Litteraturen er lite konsistent og QEEG er fortsatt mest nyttig som et forskningsverktøy ved depressive lidelser.

\section{SCHIZOFRENI}

Det er mange rapporter om signifikante avvik i EEG mellom schizofrene og kontrollpersoner. John og medarbeidere fant høyresidig amplitudeovervekt i alle frekvensbånd hos depressive og schizofrene psykotiske pasienter (33). Ved schizofreni fant Gordon og medarbeidere $ø$ kt høyresidig frontal alfaovervekt (34). Forskningsinteressen er nå stor omkring gammabølger (35). Økt mengde langsom EEG-aktivitet hos medisinerte og ikke-medisinerte schizofrenipasienter ( $3 \underline{6})$ kan også skyldes døsighet fordi schizofrene sover mindre enn friske (37.) og har færre søvnspindler (3르). Litteraturen er av variabel kvalitet og funnene er ikke konsistente. Vi har derfor fortsatt ingen robust QEEG-metode som gir spesifikk informasjon om schizofrenidiagnosen.

KAN EEG/QEEG FORUTSI RESPONS PÅ MEDIKAMENTELL BEHANDLING I PSYKIATRIEN?

Målsettingen er å unngå uker med «unødvendig» antidepressiv behandling hos pasienter som ikke vil respondere (39.). Forskjellige QEEG-markører korrelerer med behandlingsrespons på antidepressiver (쓰, $4 \underline{1}$ ), men det er umulig å forutsi resultatet hos enkeltpasienter (30). Prognostiske QEEG-teknikker kan derfor ennå ikke brukes i den kliniske hverdagen.

Forskningslitteraturen om QEEG ved depresjon, bipolar lidelse og schizofreni domineres dessverre av små studier uten blindet evaluering, og selv i omfattende oversiktsartikler har man ikke fors $\emptyset \mathrm{kt}$ å vurdere metodekvaliteten $(42,43)$. QEEG er allikevel et nyttig forskningsverktøy fordi det er vanskelig å kvantifisere normalgrenser i en visuell EEGtolking (44.). Vi vil sterkt understreke at fremtidige studier må være blindet og inkludere tilstrekkelig antall kontroller, pasienter og pasientkontroller dersom man skal ha håp om å finne robuste psykiatriske QEEG-markører i fremtiden.

\section{Konklusjon}

EEG er indisert ved nyoppståtte psykoser, tilstander med hurtige endringer i affekt, og tilstander med fluktuerende eller progredierende kognitiv reduksjon. Hensikten er å undersøke hvorvidt pasienten kan ha epileptisk eller langsom EEG-aktivitet. Epileptiform aktivitet er et spesifikt tegn på epileptisk etiologi eller komorbidetet. Langsom EEGaktivitet kan være et uspesifikt tegn på hjernesykdom som ofte bør utløse ytterligere nevrologisk utredning. Ved kortvarige og stereotype endringer av atferd hos pasienter med psykiatrisk sykdom bør epilepsi mistenkes. Epileptiske anfall kan også manifestere seg som, eller utløse, psykiatriske symptomer. Ved mistanke om en underliggende epilepsi kan allmennlegen også henvise pasienten til EEG.

Diagnostisk EEG bør tolkes av spesialist i klinisk nevrofysiologi. Det er så mange feilkilder som må identifiseres og elimineres at en eventuell QEEG-analyse også kun bør utføres som et supplement til en visuell EEG-tolking $(45,4 \underline{6})$. Patologiske funn på EEG vil øke indikasjonen for bruk av antiepileptika sammenliknet med andre psykotrope medikamenter uansett psykiatrisk hovedsymptom.

\section{HOVEDBUDSKAP}

Pasienter med nyoppståtte psykoser bør utredes for hjernepatologiske forandringer med standard EEG 
Psykiatriske pasienter med brå eller stereotype anfallsvise endringer i bevissthet, atferd eller stemningsleie bør også utredes for epilepsi med EEG

Kvantitativ EEG-analyse (QEEG) har ingen sikker klinisk nytteverdi ved depresjon eller schizofreni og må tolkes av klinisk nevrofysiolog i sammenheng med vanlig EEG

\section{LITTERATUR}

1. Herigstad A, Stefansdottir S, Aurlien H. EEG - når og hvordan? Tidsskr Nor Legeforen 2013; 133: 4852. [PubMed]

2. Kerr MP, Mensah S, Besag F et al. International consensus clinical practice statements for the treatment of neuropsychiatric conditions associated with epilepsy. Epilepsia 2011; 52: 2133-8. [PubMed] [CrossRef]

3. Henning O, Nakken KO. Epilepsi og depresjon. Tidsskr Nor Legeforen 2011; 131: 1298-301. [PubMed]

4. Kanner AM. Depression and epilepsy: a bidirectional relation? Epilepsia 2011; 52 (suppl 1): 21-7. [PubMed] [CrossRef]

5. Chang YT, Chen PC, Tsai IJ et al. Bidirectional relation between schizophrenia and epilepsy: a population-based retrospective cohort study. Epilepsia 2011; 52: 2036-42. [PubMed] [CrossRef]

6. Nuwer M. Assessment of digital EEG, quantitative EEG, and EEG brain mapping: report of the American Academy of Neurology and the American Clinical Neurophysiology Society. Neurology 1997; 49: 277-92. [PubMed] [CrossRef]

7. Coburn KL, Lauterbach EC, Boutros NN et al. The value of quantitative electroencephalography in clinical psychiatry: a report by the Committee on Research of the American Neuropsychiatric Association. J Neuropsychiatry Clin Neurosci 2006; 18: 46o-50o. [PubMed] [CrossRef]

8. Uhlhaas PJ, Singer W. Abnormal neural oscillations and synchrony in schizophrenia. Nat Rev Neurosci 2010; 11:100-13. [PubMed] [CrossRef]

9. Nuwer MR. Quantitative EEG: II. Frequency analysis and topographic mapping in clinical settings. J Clin Neurophysiol 1988; 5: 45-85. [PubMed] [CrossRef]

10. Saunte C, Øygarden J, Sand T. Topografisk kartlegging av elektrisk hjerneaktivitet. Tidsskr Nor Lægeforen 1992; 112: 1174-7.

11. Wang XJ. Neurophysiological and computational principles of cortical rhythms in cognition. Physiol Rev 2010; 90: 1195-268. [PubMed] [CrossRef]

12. Herrmann CS, Demiralp T. Human EEG gamma oscillations in neuropsychiatric disorders. Clin Neurophysiol 2005; 116: 2719-33. [PubMed] [CrossRef]

13. Colgin LL, Denninger T, Fyhn M et al. Frequency of gamma oscillations routes flow of information in the hippocampus. Nature 2009; 462:353-7. [PubMed] [CrossRef]

14. Klimesch W. EEG alpha and theta oscillations reflect cognitive and memory performance: a review and analysis. Brain Res Brain Res Rev 1999; 29: 169-95. [PubMed] [CrossRef]

15. Pascual-Marqui RD, Michel CM, Lehmann D. Low resolution electromagnetic tomography: a new method for localizing electrical activity in the brain. Int J Psychophysiol 1994; 18: 49-65. [PubMed] [CrossRef]

16. He Y, Evans A. Graph theoretical modeling of brain connectivity. Curr Opin Neurol 2010; 23:34150. [PubMed]

17. Markand ON. Brenner RP. Organic brain syndromes and dementias. I: Ebersole JS, Pedley TA, red. Current practice of clinical electroencephalography.3. utg. Philadelphia: Lippincott Williams and Wilkins, 2003: 378-404.

18. Prüss H, Dalmau J, Arolt V et al. Anti-NMDA-rezeptor encephalitis. Nervenarzt 2010; 81:396-408. [PubMed] [CrossRef]

19. Mula M, Marotta AE, Monaco F. Epilepsy and bipolar disorders. Expert Rev Neurother 2010; 10:1323. [PubMed] [CrossRef]

20. Elliott B, Joyce E, Shorvon S. Delusions, illusions and hallucinations in epilepsy: 2. Complex phenomena and psychosis. Epilepsy Res 2009; 85: 172-86. [PubMed] [CrossRef]

21. Kellaway P. An orderly approach to visual analysis. I: Daly DD, Pedley TA, red. Current practice of clinical electroencephalography. 2. utg. New York: Raven Press 1990: 139-99.

22. Bjørk MH, Sand T, Bråthen G et al. Quantitative EEG findings in patients with acute, brief depression combined with other fluctuating psychiatric symptoms: a controlled study from an acute 
psychiatric department. BMC Psychiatry 2008; 8: 89. [PubMed] [CrossRef]

23. Vaaler AE, Morken G, Linaker OM et al. Symptoms of epilepsy and organic brain dysfunctions in patients with acute, brief depression combined with other fluctuating psychiatric symptoms: a controlled study from an acute psychiatric department. BMC Psychiatry 2009; 9: 63. [PubMed] [CrossRef]

24. O'Sullivan SS, Mullins GM, Cassidy EM et al. The role of the standard EEG in clinical psychiatry. Hum Psychopharmacol 2006; 21: 265-71. [PubMed] [CrossRef]

25. Tsopelas ND, Saintfort R, Fricchione GL. The relationship of psychiatric illnesses and seizures. Curr Psychiatry Rep 2001; 3: 235-42. [PubMed] [CrossRef]

26. Leucht S, Kissling W, McGrath J et al. Carbamazepine for schizophrenia. Cochrane Database Syst Rev 2007; nr. 3: CDoo1258. [PubMed]

27. Brewerton TD. The phenomenology of psychosis associated with complex partial seizure disorder. Ann Clin Psychiatry 1997; 9:31-51. [PubMed] [CrossRef]

28. Reeves RR, Struve FA, Patrick G. Does EEG predict response to valproate versus lithium in patients with mania? Ann Clin Psychiatry 2001; 13: 69-73. [PubMed] [CrossRef]

29. Pollock VE, Schneider LS. Quantitative, waking EEG research on depression. Biol Psychiatry 1990; 27: 757-8o. [PubMed] [CrossRef]

30. Iosifescu DV, Greenwald S, Devlin P et al. Frontal EEG predictors of treatment outcome in major depressive disorder. Eur Neuropsychopharmacol 2009; 19: 772-7. [PubMed] [CrossRef]

31. Kwon JS, Youn T, Jung HY. Right hemisphere abnormalities in major depression: quantitative electroencephalographic findings before and after treatment. J Affect Disord 1996; 40: 169-73. [PubMed] [CrossRef]

32. Coutin-Churchman P, Añez Y, Uzcátegui M et al. Quantitative spectral analysis of EEG in psychiatry revisited: drawing signs out of numbers in a clinical setting. Clin Neurophysiol 2003; 114: 2294-306. [PubMed] [CrossRef]

33. John ER, Prichep LS, Winterer G et al. Electrophysiological subtypes of psychotic states. Acta Psychiatr Scand 2007; 116: 17-35. [PubMed] [CrossRef]

34. Gordon E, Palmer DM, Cooper N. EEG alpha asymmetry in schizophrenia, depression, PTSD, panic disorder, ADHD and conduct disorder. Clin EEG Neurosci 2010; 41:178-83. [PubMed] [CrossRef]

35. Uhlhaas PJ. High-frequency oscillations in schizophrenia. Clin EEG Neurosci 2011; 42: 77-82. [PubMed] [CrossRef]

36. Boutros NN, Arfken C, Galderisi S et al. The status of spectral EEG abnormality as a diagnostic test for schizophrenia. Schizophr Res 2008; 99: 225-37. [PubMed] [CrossRef]

37. Sarkar S, Katshu MZ, Nizamie SH et al. Slow wave sleep deficits as a trait marker in patients with schizophrenia. Schizophr Res 2010; 124: 127-33. [PubMed] [CrossRef]

38. Ferrarelli F, Huber R, Peterson MJ et al. Reduced sleep spindle activity in schizophrenia patients. Am J Psychiatry 2007; 164: 483-92. [PubMed] [CrossRef]

39. Iosifescu DV. Electroencephalography-derived biomarkers of antidepressant response. Harv Rev Psychiatry 2011; 19:144-54. [PubMed] [CrossRef]

40. Hunter AM, Cook IA, Leuchter AF. The promise of the quantitative electroencephalogram as a predictor of antidepressant treatment outcomes in major depressive disorder. Psychiatr Clin North Am 2007;30: 105-24. [PubMed] [CrossRef]

41. Korb AS, Hunter AM, Cook IA et al. Rostral anterior cingulate cortex theta current density and response to antidepressants and placebo in major depression. Clin Neurophysiol 2009;120:1313-9. [PubMed] [CrossRef]

42. Shelley BP, Trimble MR, Boutros NN. Electroencephalographic cerebral dysrhythmic abnormalities in the trinity of nonepileptic general population, neuropsychiatric, and neurobehavioral disorders. J Neuropsychiatry Clin Neurosci 2008; 20: 7-22. [PubMed] [CrossRef]

43. Shelley BP, Trimble MR. "All that spikes is not fits», mistaking the woods for the trees: the interictal spikes-an «EEG chameleon» in the interface disorders of brain and mind: a critical review. Clin EEG Neurosci 2009; 40: 245-61. [PubMed]

44. Boutros N, Mirolo HA, Struve F. Normative data for the unquantified EEG: examination of adequacy for neuropsychiatric research. J Neuropsychiatry Clin Neurosci 2005; 17: 84-90. [PubMed] [CrossRef]

45. Nuwer MR. Quantitative EEG: I. Techniques and problems of frequency analysis and topographic mapping. J Clin Neurophysiol 1988; 5:1-43. [PubMed] [CrossRef] 
46. Nuwer MR, Lehmann D, da Silva FL et al. IFCN guidelines for topographic and frequency analysis of EEGs and EPs. Electroencephalogr Clin Neurophysiol Suppl 1999; 52: 15-20. [PubMed]

Publisert: 11. juni 2013. Tidsskr Nor Legeforen. DOI: 10.4045/tidsskr.12.1253

Mottatt 23.10. 2012, første revisjon innsendt 5.2. 2013, godkjent 24.4. 2013. Medisinsk redaktør Siri

Lunde Strømme.

(C) Tidsskrift for Den norske legeforening 2023. Lastet ned fra tidsskriftet.no 26. april 2023. 